Sermonti, G. (1956). J. gen. Microbiol. 15, 599-608

\title{
Complementary Genes which Affect Penicillin Yields
}

\author{
BY G. SERMONTI \\ International Research Centre for Chemical Microbiology, \\ Istituto Superiore di Sanità, Rome, Italy
}

\begin{abstract}
SUMMARY: Two loci which affect the production of penicillin by Penicillium chrysogenum have been identified. Capacity to produce penicillin is suppressed by eight mutant alleles at one of the loci, and a marked decrease of yield accompanied by an effect on conidium colour is produced by one mutant allele at the other locus. The two loci are on different chromosomes. The wild type alleles of the two genes restore penicillin production in the heterokaryotic and heterozygous conditions but not when they are carried in different mycelia in mixed culture. Haploid and diploid strains have been identified among the segregants from a heterozygous diploid.
\end{abstract}

In a previous work (Caglioti \& Sermonti, 1956) five strains of Penicillium chrysogenum Thom which had been rendered non-producers of penicillin by four independent mutations were studied. Balanced heterokaryons and heterozygous diploids were synthesized, combining two by two four mutants in all possible ways, but no production of penicillin was obtained from any combination. Thus it was shown that the five genotypes in question are not complementary in respect of penicillin biosynthesis. The present work was planned with a view to extending these studies. One of the strains used in the previous work was taken as a test strain, and five other non-producing mutants were tested for their complementarity with it. A positive result has been obtained in this second attempt.

\section{METHODS}

The media, techniques and symbols used in the present paper are the same as those used in the previous paper (Caglioti \& Sermonti, 1956) to which the reader is referred. Shake-flask submerged cultures were standardized as follows.

Submerged culture. Spores for the seed flask were collected from week-old cultures on husked barley moistened with a sporulating solution consisting of $3 \%(\mathrm{w} / \mathrm{v})$ glycerol and $0.1 \%(\mathrm{w} / \mathrm{v})$ asparagine in water. A dense suspension of spores was inoculated in $500 \mathrm{ml}$. Ignis glass flasks having $40 \mathrm{~mm}$. mouths and cotton-wool plugs, each containing $100 \mathrm{ml}$. of the following medium: $80 \mathrm{~g}$. corn steep liquor; $60 \mathrm{~g}$. dextrin; tap water to 11 . The $\mathrm{pH}$ value was brought to $5 \cdot 2$ with $\mathrm{NaOH}$ before autoclaving at $120^{\circ}$ for $20 \mathrm{~min}$. After $48 \mathrm{hr}$. of incubation $5 \mathrm{ml}$. of the culture were transferred to flasks of the same type containing $60 \mathrm{ml}$. of the following medium: $70 \mathrm{~g}$. corn steep liquor; $4.5 \mathrm{~g}$. lactose; tap water to 11 . The $\mathrm{pH}$ value was 4.6 before sterilization (as above); no correction of $\mathrm{pH}$ value was made. $\mathrm{CaCO}_{3}(0 \cdot 6 \mathrm{~g}$.; separately sterilized) was then added to each flask. Other additions, per flask, were: $6 \%(w / v)$ anti-foam 
E 100 (made by Bayer-Leverkusen) in lard oil, $0.1 \mathrm{ml}$. added with inoculum; $10 \%(\mathrm{w} / \mathrm{v})$ sodium phenylacetate, $\mathbf{0 . 3} \mathrm{ml}$. every $24 \mathrm{hr}$. starting at $24 \mathrm{hr}$. The cultures were incubated at $24^{\circ}$ on a rotary shaker (Paladino, 1954).

Organisms. Strain $65 \mathrm{pr} y_{3} p_{2}$, a non-penicillin-producing strain of Penicillium chrysogenum (Caglioti \& Sermonti, 1956), was used as test strain and was crossed with the new strains to be tested. The origin and characteristics of the mutants obtained are set out in Table 1. Strains $93 p_{5}, 98 p_{6}, 109 p_{7} y_{1}$ and $110 p_{8} y_{1}$ kept their morphological characteristics after losing capacity to produce penicillin by mutation. Strain $96 p_{9}$ showed a diminution of its production capacity to about a tenth that of the original strain, accompanied by a grey coloration of the conidia. The hypothesis that these two modifications are the result of a single mutation is suggested by their simultaneous appearance and by the fact that the two characters in question always segregated together from heterozygous diploid XXIX (see below).

Table 1. Mutants of Penicillium chrysogenum obtained in the course

$$
\text { of the present work }
$$

\begin{tabular}{|c|c|c|c|c|}
\hline $\begin{array}{c}\text { Strain } \\
\text { symbol* }\end{array}$ & $\begin{array}{l}\text { Parent } \\
\text { strain }\end{array}$ & $\begin{array}{l}\text { Conidium } \\
\text { colour }\end{array}$ & $\begin{array}{l}\text { Nutritional } \\
\text { requirement }\end{array}$ & $\begin{array}{c}\text { Comparative } \\
\text { penicillin } \\
\text { yield } \dagger \\
(47.1564 \\
\text { Wis. }=100)\end{array}$ \\
\hline 47.1564 Wis. & - & Green & None & 100 \\
\hline $15 y_{1}$ & 47.1564 Wis. & Yellow & None & $113 \cdot 9$ \\
\hline $96 p_{\theta}$ & 47.1564 Wis. & Grey & None & $10 \cdot 2$ \\
\hline $98 p_{6}$ & 47. 1564 Wis. & Green & None & $\mathbf{0}$ \\
\hline $93 p_{5} y_{1}$ & $15 y_{1}$ & Yellow & None & $\mathbf{0}$ \\
\hline $109 p_{7} y_{1}$ & $15 y_{1}$ & Yellow & None & $\mathbf{0}$ \\
\hline $110 p_{8} y_{1}$ & $15 y_{1}$ & Yellow & None & $\mathbf{0}$ \\
\hline 147 ad $p_{9}$ & $96 p_{9}$ & Grey & Adenine & - \\
\hline 162 nic $p_{9}$ & $96 p_{9}$ & Grey & Nicotinamide & - \\
\hline 163 ly $p_{\theta}$ & $96 p_{9}$ & Grey & Lysine & 一 \\
\hline 158 hy $p_{6}$ & $98 p_{8}$ & Green & Hypoxanthine & - \\
\hline $144 m e p_{5} y_{1}$ & $93 p_{5} y_{1}$ & Yellow & Methionine & - \\
\hline 148 me $_{7} y_{1}$ & $109 p_{7} y_{1}$ & Yellow & Methionine & - \\
\hline $157 h y p_{8} y_{1}$ & $110 p_{8} y_{1}$ & Yellow & Hypoxanthine & - \\
\hline
\end{tabular}

* The strain symbols consist of a code number followed by symbols as follows: $y=$ yellow conidium colour; $p=$ absence or marked reduction in penicillin production; $l y=l y s i n e$ requirement; $a d=$ adenine requirement; $n i c=$ nicotinamide requirement; $h y=$ hypoxanthine requirement; $m e=$ methionine requirement. Different subscripts indicate different mutations.

$\dagger$ Penicillin yields at day of maximum titre in submerged culture. Three flasks in each run. Maximum yield of 47.1564 Wis : 620 units $/ \mathrm{ml}$. at $120 \mathrm{hr}$.

\section{RESULTS}

\section{Investigation of mutants $\mathrm{p}_{5}, \mathrm{p}_{6}, \mathrm{p}_{7}$ and $\mathrm{p}_{8}$}

The first part of the present work concerned the study of strains $93 p_{5} y_{1}, 98 p_{6}$, $109 p_{7} y_{1}$ and $110 p_{8} y_{1}$. Four suitably marked derivatives from these strains (144 me $p_{5} y_{1}, 158 h y p_{6}, 148 m e p_{7} y_{1}$ and $157 h y p_{8} y_{1}$, respectively) were used in the synthesis of four balanced heterokaryons with the strain $65 \operatorname{pr} y_{3} p_{2}$. All the heterokaryons were obtained as syntrophic tufts on a limiting medium made up of a $1: 5$ mixture of complete and minimal medium (Sermonti \& 
Spada-Sermonti, 1954). From these four heterokaryons were isolated the corresponding four heterozygous diploids, XXII (65/144), XXIII (65/157) and XXIV (65/158) as sectors from heterokaryons, and diploid XXVII (65/148) as a colony growing on minimal medium after plating spores of the corresponding heterokaryon.

The diploids were purified by isolation of single conidia with a micromanipulator (Sermonti, 1954a). They were all prototrophic and had green conidia as was to be expected, since the factor $y_{3}$ of strain 65 was already known to be non-allelic to $y_{1}$ of strains 93,109 and 110, and both are known to be recessive (Caglioti \& Sermonti, 1956). In submerged culture all the heterozygous diploids proved to be non-penicillin-producing, like their component strains (see Table 2). This part of the work thus confirms and extends the results of Caglioti \& Sermonti's (1956) paper.

\section{Investigation of mutant $\mathrm{p}_{9}$}

The second part of the work concerns the study of strain $96 p_{9}$. Three different mutants $\left(147\right.$ ad $p_{9}, 162$ nic $p_{9}$ and 163 ly $\left.p_{9}\right)$ were derived from this strain and used to synthesize three balanced heterokaryons with the test strain 65 pr $y_{3} p_{2}$ by the techniques already mentioned. The three corresponding heterozygous diploids, XXXII (65/147), XXXIII (65/162) and XXIX (65/163) were isolated as sectors from the balanced heterokaryons. They were purified by isolation of a single conidium and proved to be prototrophic with green spores. On testing in submerged culture they turned out to be normal penicillin producers (see Table 2 ).

Table 2. Penicillin production in submerged culture by heterozygous diploids between strains mutant for penicillin-producing capacity

$\begin{array}{ll}\text { Code } & \text { Component strains } \\ \text { XXII } & 65 p r y_{3} p_{2} / 144 \text { me } p_{5} y_{1} \\ \text { XXIII } & 65 p r y_{3} p_{2} / 157 \text { hy } p_{8} y_{1} \\ \text { XXIV } & 65 p r y_{3} p_{2} / 158 \text { hy } p_{6} \\ \text { XXVII } & 65 p r y_{3} p_{2} / 148 \text { me } p_{7} y_{1} \\ \text { XXIX } & 65 p r y_{3} p_{2} / 163 \text { ly } p_{9} \\ \text { XXXII } & 65 p r y_{3} p_{2} / 147 \text { ad } p_{9} \\ \text { XXXIII } & 65 p r y_{3} p_{2} / 162 \text { nic } p_{9} \\ \text { XXXV } & 63 c y p_{3} y_{1} / 163 \text { ly } p_{9}\end{array}$

47. 1564, Wis. (haploid)
Penicillin production* (units/ml.)

$\begin{array}{cr}96 \mathrm{hr} . & 120 \mathrm{hr} . \\ 0 \cdot 2 & 0 \cdot 3 \\ 0 \cdot 2 & 0 \cdot 3 \\ 0 & - \\ 0 & - \\ 342 & 436 \\ 215 & 244 \\ 291 & 307 \\ 175 & 212 \\ 350 & 551\end{array}$

* Every figure is the average of two values.

Fig. 1 shows the rate of penicillin production by diploid XXIX 65 pr $y_{3} p_{2} /$ 163 ly $p_{9}$ in shake flasks as compared with those of strains $99 p_{2}$ and $96 p_{9}$ and with the wild type strain $47.1564 \mathrm{Wis}$. from which both are descended. In the same figure is shown the rate of penicillin production by a mixed culture of strains $99 p_{2}$ and $96 p_{9}$ (see below). Production by the diploid strain is 
practically as good as that of the wild type strain, while the component strains give very reduced yields $\left(96 p_{9}\right)$ or none at all $\left(99 p_{2}\right)$.

A heterozygous diploid (XXXV) was synthesized between the non-penicillinproducing strain $63 c y p_{3} y_{1}$ (Caglioti \& Sermonti, 1956) and strain 163 ly $p_{9}$ by using the same techniques. On testing in submerged culture this strain also proved to be penicillin-producing, but its yield of penicillin was less than those

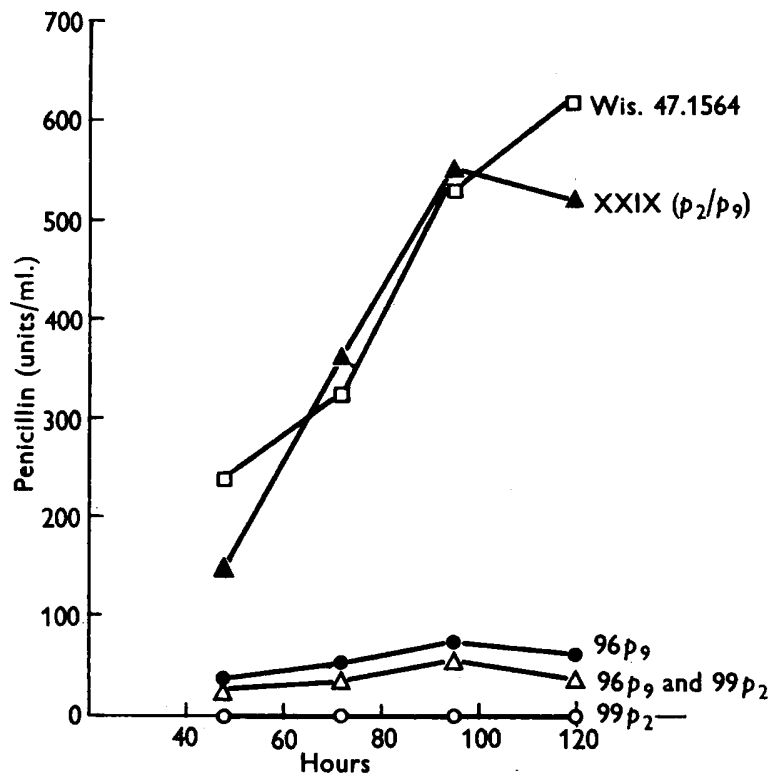

Fig. 1. Penicillin production in submerged culture by strains : $47.1564 \mathrm{Wis}$; $99 p_{2} ; 96 p_{0}$; $99 p_{2}$ and $96 p_{9}$ in mixed culture; diploid XXIX 65 pr $y_{3} p_{2} / 163$ ly $p_{9}$. Medium : corn steep, lactose. Four flasks in each run.

of heterozygous diploids containing the allele $p_{2}$ (Table 2). The marked phenotypic expression of allele $p_{3}$ in the heterozygous state has already been remarked upon (Caglioti \& Sermonti, 1956).

Production of penicillin by $\mathrm{p}_{9}+\mathrm{p}_{2}$ heterokaryons and $\mathrm{p}_{9}$ and $\mathrm{p}_{2}$ mixed culture

With a view to determining the level at which the complementary effect between the genotypes $p_{2} P_{9}$ and $P_{2} p_{9}$ takes effect, two balanced heterokaryons carrying these allele combinations and a mixed culture of the strains $99 p_{2} P_{9}$ and $96 P_{2} p_{9}$ (referred to above as $99 p_{2}$ and $96 p_{9}$ ) were examined for their penicillin production. The balanced heterokaryons were tested in surface culture on minimal agar (Jarvis \& Johnson, 1950) with the technique described by Caglioti \& Sermonti (1956). Auxanographic tests were used (Sermonti, 1954a) to check the heterokaryotic nature of these colonies. Table 3 gives the data for penicillin production; it appears from this table that the penicillin yield of balanced heterokaryons is perfectly comparable with that of heterozygous diploid XXIX and the wild type strain 47.1564 Wis. 
The mixed culture of strains $96 P_{2} p_{y}$ and $99 p_{2} P_{9}$ was effected in shake flasks. The two strains were separately seeded in the seed flasks, and after $48 \mathrm{hr} .2 .5 \mathrm{ml}$. of each culture were transferred into one flask of the same fermentation medium. The experiment was conducted simultaneously with that described in the last section and reported in Fig. 1; the results are also shown in Fig. 1. The penicillin yield of the mixed culture was very low, roughly intermediate between those of the separate component strains.

Table 3. Penicillin production in surface culture on minimal agar by two $\mathrm{p}_{2}+\mathrm{p}_{9}$ heterokaryons compared with a $\mathrm{p}_{2} / \mathrm{p}_{9}$ heterozygous diploid and other strains

A plug of agar is removed from the edge of the colony and placed on agar inoculated with Bacillus subtilis. After incubation overnight at $37^{\circ}$ the inhibition halo is measured. Penicillin production is calculated by reference to a standard curve (yield of diploid XXIX at the 11th day $=500$ ). Each figure is the average of four values, two from each of two distinct cultures. Different cultures were sampled on different days.

\begin{tabular}{|c|c|c|c|c|c|c|}
\hline \multirow{2}{*}{$\begin{array}{l}\text { Age of } \\
\text { the culture } \\
\text { in days }\end{array}$} & \multicolumn{6}{|c|}{ Strains } \\
\hline & $96 p_{9}$ & $99 p_{2}$ & $\begin{array}{c}\operatorname{XXIX} 65 / 163 \\
\left(p_{2} / p_{9}\right)\end{array}$ & $\begin{array}{l}65+163 \\
\left(p_{2}+p_{8}\right)\end{array}$ & $\begin{array}{l}65+162 \\
\left(p_{2}+p_{9}\right)\end{array}$ & 47.1564 Wis \\
\hline 6 & 5 & $\mathbf{0}$ & 37 & 32 & 37 & $\mathbf{5 5}$ \\
\hline 7 & 35 & $\mathbf{0}$ & 170 & 150 & 170 & 220 \\
\hline 11 & 129 & $\mathbf{0}$ & 500 & - & 530 & 550 \\
\hline
\end{tabular}

Variation of $\mathrm{pH}$ value in the culture medium

Penicillin production is particularly sensitive to changes in $\mathrm{pH}$ value of the medium. Good production may be obtained at $\mathrm{pH}$ values between $6 \cdot 8$ and $7 \cdot 8$ (Johnson, 1953). The pH value of the culture media was constantly checked during the runs. In cultures of strain 47.1564 Wis. the $\mathrm{pH}$ value $24 \mathrm{hr}$. after inoculation was generally $7 ;$;it then fell to values between 6.5 and 6.8 at $48 \mathrm{hr}$., to rise again until at $120 \mathrm{hr}$. it reached about $\mathrm{pH} 8$. In cultures of strain $96 p_{9}$ the $\mathrm{pH}$ decrease at $48 \mathrm{hr}$. was appreciably more marked, but the $\mathrm{pH}$ value then returned to optimal values. In cultures of strain $99 p_{2}$ the flexion at $48 \mathrm{hr}$. was not observed, and the $\mathrm{pH}$ value kept to optimal values for a longer period. Thus for a large part of the run with either strain the $\mathrm{pH}$ of the medium was perfectly compatible with normal penicillin production. The behaviour of the $\mathrm{pH}$ value in runs with heterozygous diploid XXIX $\left(p_{9} / p_{2}\right)$ was intermediate between those of strains $96 p_{9}$ and $99 p_{2}$, and that of the mixed culture $96 p_{9}$ and $99 p_{2}$ was very similar to that observed in the diploid culture. Yet the diploid gave normal penicillin yields, while yields from the mixed culture were very low.

\section{Genetic analysis of diploid XXIX}

Size of conidia of segregant strains. Diploid XXIX 65 pr $y_{3} p_{2} / 163$ ly $p_{9}$ was genetically analysed by an examination of its somatic segregation. Attention was paid to the size of the conidia of the segregant strains, which has not previously been done in analyses of segregants from diploids of Penicillium 
chrysogenum (Sermonti, 1954b; Caglioti \& Sermonti, 1956; Sermonti, to be published). It was possible to classify the various clones into two groups according to the size of their conidia: some presented conidia of an average diameter close to that of the original diploid, others close to that of the haploid component strains (Table 4). The measurements were carried out on conidia

Table 4. Average volume and diameter of the conidia of diploid XXIX, its component strains and its segregants

\begin{tabular}{|c|c|}
\hline \multicolumn{2}{|c|}{ Strain } \\
\hline Code & Phenotype* \\
\hline $\begin{array}{l}65 \\
163 \\
\text { XXIX }\end{array}$ & $\begin{array}{l}p r y_{3} p_{2} \\
l y p_{9} \\
+\end{array}$ \\
\hline
\end{tabular}

\section{1}

697.4

714.133

714.144

697.6

642.1

714.138

714.118

642.3

714.4

697.12

745.14ł

$p r$
$p r$
$p r$
$p r$
ly $p$
ly $p p r$
$p r$
$p r$
$y p$
$y p$
$p r$
$p r l y p$

\begin{tabular}{|c|c|}
\hline \multicolumn{2}{|c|}{ Size of conidia } \\
\hline $\begin{array}{c}\text { Diameter } \dagger \\
(\mu .)\end{array}$ & $\begin{array}{l}\text { Corresponding } \\
\text { volume }\left(\mu .^{3}\right)\end{array}$ \\
\hline $\mathbf{3 \cdot 9 8}$ & $\mathbf{3 3} \cdot \mathbf{0}$ \\
\hline $\mathbf{3} \cdot \mathbf{8 3}$ & $29 \cdot 4$ \\
\hline $5 \cdot 24$ & $75 \cdot 3$ \\
\hline \multicolumn{2}{|c|}{ Segregants } \\
\hline $4 \cdot 10$ & $36 \cdot 1$ \\
\hline $4 \cdot 18$ & $38 \cdot 2$ \\
\hline $3 \cdot 97$ & $32 \cdot 8$ \\
\hline $3 \cdot 84$ & $29 \cdot 6$ \\
\hline $3 \cdot 73$ & $27 \cdot 2$ \\
\hline 4.98 & $64 \cdot 7$ \\
\hline 4.98 & 64.7 \\
\hline $5 \cdot 24$ & $75 \cdot 3$ \\
\hline $5 \cdot 04$ & $67 \cdot 0$ \\
\hline $5 \cdot 21$ & $74 \cdot 0$ \\
\hline $5 \cdot 15$ & $71 \cdot 4$ \\
\hline $5 \cdot 36$ & $80 \cdot 6$ \\
\hline
\end{tabular}

\section{Classification \\ Haploid \\ Haploid \\ Diploid}

Haploid
Haploid
Haploid
Haploid
Haploid
Diploid
Diploid
Diploid
Diploid
Diploid
Diploid
Diploid

Haploid

Haploid

Haploid

Haploid

Diploid

Diploid

Diploid

Diploid

Diploid

* The allele symbols indicate the phenotype in both haploids and diploids.

$\dagger$ The diameter given is the average taken from measurements of 50 conidia in each case. $\ddagger$ See Table 5 .

collected with a loop in a drop of water containing $c .10 \%$ sodium laurylsulphonate; this was placed on a microscope slide and covered with a cover-glass. The conidia were isolated or, exceptionally, were in very short chains, and of various shapes ranging from spherical (the commonest) to ellipsoidal. Measurements were made of the diameter of the spherical conidia, and of the major and minor axes of the ellipsoidal conidia, taking the average between them. The measurements were carried out with a Spencer eyepiece micrometer (calibrated: 1 division $=1 \cdot 70 \mu$., useful approximation 1/10 of a division). The averages given in Table 4 are from measurements of 50 conidia for each strain. The overall average diameter of the conidia of strains with normal conidia was 3.95 $\mu$. and of strains with giant conidia $5 \cdot 15 \mu$.; the ratio between these two values is $1 \cdot 3$, corresponding to a ratio between volumes of about 2 .

In the case of the strains not included in Table 4 enough conidia were measured to classify the strain with reasonable certainty in one of the two groups. Some colonies presented conidia of extremely variable size: these were purified by isolation of single conidia and the diameter of conidia measured in the pure colonies.

The segregants selected included a very high proportion of clones with 
normal conidia; giant conidia were found in only eight segregants out of a total of 106 (see Table 6 ).

Four segregants bearing normal conidia and four segregants bearing large conidia were purified by isolation of single conidia with a micromanipulator and examined for further segregation; the latter produced further segregants, showing that they still possessed heterozygous genes, while the former produced no second-order segregants (Table 5). These results suggest, especially in view of the findings of Pontecorvo, Tarr Gloor \& Forbes (1954) on mitotic segregation in Aspergillus nidulans, that the segregants bearing small conidia are haploid and the segregants bearing large conidia diploid. They will be so considered here.

Table 5. Second-order segregation from some first-order segregants from diploid $X X X I$ related to conidia volume

\begin{tabular}{|c|c|c|c|c|c|c|}
\hline \multirow{2}{*}{\multicolumn{2}{|c|}{ First-order segregants }} & \multirow{3}{*}{$\begin{array}{c}\text { Conidium } \\
\text { diameter* } \\
(\mu .)\end{array}$} & \multicolumn{2}{|c|}{ Colonies examined } & \multirow{2}{*}{\multicolumn{2}{|c|}{$\begin{array}{c}\text { Segregants } \\
\text { obtained }\end{array}$}} \\
\hline & & & \multirow{2}{*}{$\begin{array}{l}\text { Selection } \\
\text { for }\end{array}$} & \multirow{2}{*}{$\begin{array}{c}\text { Total } \\
\text { examined } \\
(\text { no. })\end{array}$} & & \\
\hline Code & Phenotype $\uparrow$ & & & & (no.) & (phenotype) \\
\hline \multicolumn{7}{|c|}{ A. Segregants with giant conidia } \\
\hline 714.138 & $p r$ & 4.98 & Colour & 660 & 1 & $y p r$ \\
\hline 714.118 & $p r$ & $\mathbf{5 \cdot 2 4}$ & Colour & 324 & 2 & $\begin{array}{l}\text { y lypr pł } \\
\text { ly prp\$ }\end{array}$ \\
\hline 714.4 & $y p$ & $5 \cdot 21$ & $\begin{array}{l}\text { Require- } \\
\text { ments }\end{array}$ & 2264 & 4 & $p r y p$ \\
\hline 679.12 & $p r$ & $5 \cdot 15$ & Colour & 1700 & 1 & $p$ pr \\
\hline \multicolumn{7}{|c|}{ B. Segregants with normal conidia } \\
\hline 714.144 & $p r$ & $\mathbf{3 \cdot 8 4}$ & Colour & 2000 & $\mathbf{0}$ & - \\
\hline 714.133 & $p r$ & $\mathbf{3 \cdot 9 7}$ & Colour & 1300 & 0 & - \\
\hline 697.4 & $p r$ & $4 \cdot 18$ & Colour & 1694 & 0 & - \\
\hline 697.1 & $p r$ & $4 \cdot 10$ & Colour & 1368 & $\mathbf{0}$ & - \\
\hline
\end{tabular}

Phenotypes of somatic segregants from diploid XXIX. Colour segregants were obtained by plating conidia of the diploid on complete medium and picking out the colonies of a colour different from the rest of the population after 1 week of growth. Yellow and grey (or at least paler than normal) colonies were transferred to fresh complete agar. Many of the pale colonies in time assumed a green colour similar to that of the wild type, darker than that of the diploid colonies. These all turned out on later testing to be haploid and to have the proline requirement. Thirty-six other colonies of a yellowish green colour were tested for requirements and conidia size; all proved to be diploid, and there were thirty-four prototrophic and two with proline requirement. Deficient segregants were selected as poorly growing colonies after plating conidia of diploid XXIX on limiting medium (Sermonti, 1954 $b$ ). All the segregants were checked for colour, tested for nutrient deficiencies and 
penicillin production on agar (Caglioti \& Sermonti, 1956), and average conidia size measured. The phenotypes of the segregants selected by the two techniques are reported in Table 6.

Table 6. Segregants* selected from diploid XXIX 65 pr $\mathrm{y}_{3} \mathrm{p}_{2} / 163$ ly $\mathrm{p}_{9}$

\begin{tabular}{|c|c|c|}
\hline & $\begin{array}{c}\text { Selected } \\
\text { for colour } \dagger\end{array}$ & $\begin{array}{l}\text { Selected } \\
\text { requireme }\end{array}$ \\
\hline & A. Haploid & \\
\hline Yellow: $p r p_{2}$ & 1 & $\mathbf{1}$ \\
\hline Grey : $l y p_{0}$ & $\mathbf{3 3}$ & 5 \\
\hline Green§: $p r P$ & 53 & 5 \\
\hline & 87 & 11 \\
\hline & B. Diploid & \\
\hline Yellow : $p r p_{2}$ & 1 & $\mathbf{0}$ \\
\hline$p_{2}$ & $\mathbf{3}$ & $\mathbf{0}$ \\
\hline Green: $p r P$ & 2 & 2 \\
\hline & 6 & 2 \\
\hline
\end{tabular}

* The allele symbols indicate the phenotype in both haploids and diploids. $P=$ produces penicillin.

$\dagger$ Out of 3698 colonies observed in one experiment. One yellow $p p_{2}$ diploid and one yellow $p_{2}$ diploid from 912 colonies observed in another experiment.

$\ddagger 75$ colonies tested out of 750 observed on limiting medium.

$\$$ The green colour of these strains changes from greyish to the dark green of the wild type, while the colour of the diploids is yellowish green.

All the mutant alleles of the component strains of diploid XXIX segregate from this strain, including $p_{2}$, complete incapacity to produce penicillin, and $p_{0}$, great diminution in penicillin yield accompanied by grey colour of the conidia; $p_{2}$ is linked to $y_{3}$ but not to $p r$, and $p_{9}$ is linked to $l y$.

Table 7 shows the penicillin yield in submerged culture of some of the

Table 7. Penicillin production in submerged culture by diploid XXIX, its component strains and its segregants

\begin{tabular}{|c|c|c|c|c|}
\hline \multirow[b]{2}{*}{ Code } & \multirow[b]{2}{*}{ Phenotype* } & \multirow[b]{2}{*}{ Ploidy† } & \multicolumn{2}{|c|}{$\begin{array}{l}\text { Penicillin production } \ddagger \\
\text { (units/ml.) }\end{array}$} \\
\hline & & & $76 \mathrm{hr}$. & $96 \mathrm{hr}$. \\
\hline 96 & $p_{9}$ & Haploid & 62 & 69 \\
\hline 163 & $l y p_{0}$ & Haploid & 41 & 51 \\
\hline 99 & $p_{2}$ & Haploid & 0 & $\mathbf{0}$ \\
\hline 65 & $p r y_{3} p_{2}$ & Haploid & $1 \cdot 0$ & $\mathbf{2 \cdot 2}$ \\
\hline XXIX & + & Diploid & 374 & 475 \\
\hline \multicolumn{5}{|c|}{ Segregants } \\
\hline 642.3 & $y p$ & Diploid & $0 \cdot 6$ & $1 \cdot 9$ \\
\hline 697.16 & pr yp & Haploid & $0 \cdot 6$ & $1 \cdot 2$ \\
\hline 697.6 & $\operatorname{lyp}$ & Haploid & 12 & 35 \\
\hline 697.7 & $\operatorname{lyp}$ & Haploid & 19 & $\mathbf{3 8}$ \\
\hline 697.4 & $p r$ & Haploid & 481 & 728 \\
\hline 697.8 & $p r$ & Haploid & 437 & 708 \\
\hline
\end{tabular}


segregant strains. Three degrees of penicillin production may be observed: haploid segregants for the proline requirement alone yield more than 700 units penicillin $/ \mathrm{ml}$., i.e. the highest yields given by 47.1564 Wis. and higher than those of the original diploid; segregants for the lysine requirement give less than a tenth of the diploid yield; yellow segregants give only traces of penicillin. Two diploid proline-dependent segregants were compared for penicillin production on agar with five haploid proline-dependent segregants, and proved to produce nearly half the yield of the latter.

\section{DISCUSSION}

The present work has led to the identification of a second locus which controls penicillin production in addition to the one identified by Caglioti \& Sermonti (1956). The nine mutant alleles which have now been examined (five in the present work and four in the previous one) include eight which belong to the same locus and one $\left(p_{9}\right)$ belonging to a second locus. The last differs from the others in exerting an effect on conidial colour and in its incomplete suppression of penicillin-producing capacity in the haploid.

The isolation of haploid segregants from the heterozygous diploid XXIX is the first instance of the complete cycle of parasexual recombination (haploiddiploid-haploid) to be reported in Penicillium chrysogenum. The presence of haploid as well as diploid segregants is a further parallel in somatic segregation behaviour between Aspergillus nidulans (Pontecorvo et al. 1954) and $P$. chrysogenum. The haploid segregants in Aspergillus are thought to be the result of irregular distribution of whole chromosomes at mitosis (Pontecorvo et al. 1954). If a similar process be assumed for the formation of haploid nuclei in $\boldsymbol{P}$. chrysogenum, the two genes $p_{2} / \boldsymbol{P}_{2}$ and $p_{9} / \boldsymbol{P}_{9}$ must be on different chromosomes, since the haploid segregants of diploid XXIX include a number giving a penicillin production as high as that of the starting strain (47 . 1564 Wis.). If the two genes were on the same chromosome, one mutant allele or the other would necessarily be present in each haploid segregant. In any case, the qualitative data of the segregation from diploid XXIX, and still more the submerged culture fermentation results with some of the segregants, indicate the genetic nature of the mutations $p_{2}$ and $p_{9}$.

The following conclusions may be drawn with respect to the genotypes $p_{2} \boldsymbol{P}_{9}$ and $\boldsymbol{P}_{2} p_{9}$. Neither determines normal penicillin production in the haploid. They do not permit normal penicillin production when they are both present in the same culture medium but in different mycelia. Penicillin production is restored when they are carried in the same cytoplasm in a balanced heterokaryon, and also when they are together in heterozygous diploid nuclei. A further appreciable increase in production occurs when the two alleles $\boldsymbol{P}_{\mathbf{g}}$ and $\boldsymbol{P}_{2}$ are together in the same haploid nucleus in the absence of the corresponding recessive alleles.

The author wishes to express his thanks to Professor G. Pontecorvo, F.R.S., for his many valuable criticisms offered in revising this paper; to Professor E. B. Chain, 
F.R.S., for interest taken in this work; to Dr M. T. Caglioti for her collaboration in the first part of the work; also to Mr F. G. Miles for the English translation of the Italian text.

\section{REFERENCES}

Caglioti, M. T. \& Sermonti, G. (1956). A study of the genetics of penicillin-producing capacity in Penicillium chrysogenum. J. gen. Microbiol. 14, 38.

Jarvis, F. G. \& Johnson, M. J. (1950). The mineral nutrition of Penicillium chrysogenum Q 176. J. Bact. 59, 51.

Johnson, M. J. (1953). Recent advances in penicillin fermentation. R.C. Ist. sup. Sanit. 15 (F.S.), 124.

Paladino, S. (1954). A simple rotary shaker. R.C. Ist. sup. Sanit. (English edition), $17,145$.

Pontecorvo, G., Tarr Gloor, E. \& Forbes, E. (1954). Analysis of mitotic recombination in Aspergillus nidulans. J. Genet. 52, 226.

Sermonti, G. (1954a). Genetics of Penicillium chrysogenum. I. Heterokaryosis in Penicillium chrysogenum. R.C. Ist. sup. Sanit. (English edition), 17, 213.

Sermonti, G. (1954b). Genetics of Penicillium chrysogenum. II. Segregation and recombination from a heterozygous diploid. R.C. Ist. sup. Sanit. (English edition), 17, 231.

Sermonti, G. \& Spada-Sermonti, I. (1954). Simplified method for the synthesis of heterokaryons in Penicillium chrysogenum. Microbial Genet. Bull. 10, 35. 